\title{
A transatlantic comparison of training in emergency medicine
}

\author{
J P Wyatt, J E Weber
}

\begin{abstract}
The system of training in accident and emergency (A\&E) medicine in the United Kingdom is at a critical and much earlier stage of development than in the United States. Transatlantic comparison offers the opportunity to explore possible ways of improving training in the United Kingdom. Comparison revealed deficiencies in the UK training system in the following: prehospital care training, formal theoretical teaching, close supervision in a clinical setting, and in-service training examinations. Implementation of measures designed to address these deficiencies would enhance UK training in $A \& E$ medicine. (F Accid Emerg Med 1998;15:175-180)
\end{abstract}

Keywords: training; USA; emergency medicine

From humble origins, emergency medicine in the United States has established itself as a highly attractive specialty. As it has matured, so has the training programme for doctors entering the specialty. The first residency programme in emergency medicine was introduced at the University of Cincinnati in 1970; by 1996 the number of programmes had increased to 127 , with an annual intake of more than 1000 residents. $^{12}$

In the United Kingdom, the equivalent specialty of accident and emergency (A\&E) medicine is currently in a phase of rapid development. Following the inception of the Faculty of A\&E Medicine in 1993 and the introduction of Calman proposals, specialist registrar training in $\mathrm{A} \& \mathrm{E}$ is also developing rapidly. ${ }^{34}$ Indeed, it is evolving in a not dissimilar fashion to that seen previously in the USA.

In its current phase of rapid development,

Accident and

Emergency

Department, Royal

Infirmary, Lauriston

Place, Edinburgh

EH3 9YW, UK

J P Wyatt

Section of Emergency Medicine, University of Michigan Medical School, 1500 East

Medical Center Drive,

Ann Arbor, Michigan

48109 - 0303, USA

J E Weber

Correspondence to: Mr Wyatt.

Accepted for publication 1 December 1997
$A \& E$ in the United Kingdom faces a considerable challenge in determining the optimal length and structure of training programmes and the best form of associated examinations. A critical comparison of training in emergency medicine in the USA with that in the United Kingdom provides an excellent opportunity for the exchange of ideas, thus enabling the current systems to be enhanced. However, there are certain limitations to such a comparison. In particular, differences in specialist transatlantic differences both in previous training and in emergency health care systems. Interestingly, despite these differences, the role of the emergency physician in the USA is in many ways remarkably similar to that in the United Kingdom. ${ }^{5}$ training need to be interpreted in the light of
The emergency physician: from school to specialist training

The education structure before the start of specialist postgraduate medical training in the USA differs considerably from that in the United Kingdom. Figure 1 compares the typical routes taken to become an independent trained practitioner in emergency medicine (termed an "attending physician" in the USA, a "consultant" in the United Kingdom).

Entry into medical school in the USA is preceded by four years at undergraduate college. During this time, it is possible to study any one of a variety of "major" subjects, but to apply for medical school it is necessary to also take certain core classes (for example, chemistry, biology, physics, and mathematics).

The medical school course in the USA lasts four years. Broadly speaking, the structure of the course is similar to the traditional British, in that the first two years are spent largely in the classroom and the last two years are spent largely in university hospitals doing clinical rotations. Interestingly, emergency medicine is not a mandatory rotation for graduation from some American medical schools. However, a medical student wishing to successfully apply to join an emergency medicine residency will almost certainly need to demonstrate that he spent some time in the emergency department.

In the United Kingdom, most students enter a five year medical school course after secondary school aged 18 years and obtain a medical degree (MB ChB or equivalent). Some extend the course by a year to study a preclinical subject in more depth and obtain a BSc or B Med Sci degree. After successfully completing a mandatory house officer year comprising six months of surgery and six months of medicine, the junior doctor becomes "fully registered" and usually enters a period of two or three years of general professional training.

\section{Entry into specialist training}

Would-be emergency physicians in the USA enter a residency programme by applying to the National Resident Matching Program. The process involves both applicants and emergency programmes ranking each other in order of preference, enabling an appropriate "match" to be made. The majority of applicants are final year medical students, a minority are residents* previously trained in other

*Throughout this article, the term "resident" refers to a junior doctor training in emergency medicine in the United States. Similarly, the term "registrar" refers to a specialist (career) registrar training in accident and emergency in the United King train. The in accident and em Kingdom. The term "emergency medicine" is used interchangeably with accident and emergency medicine. 


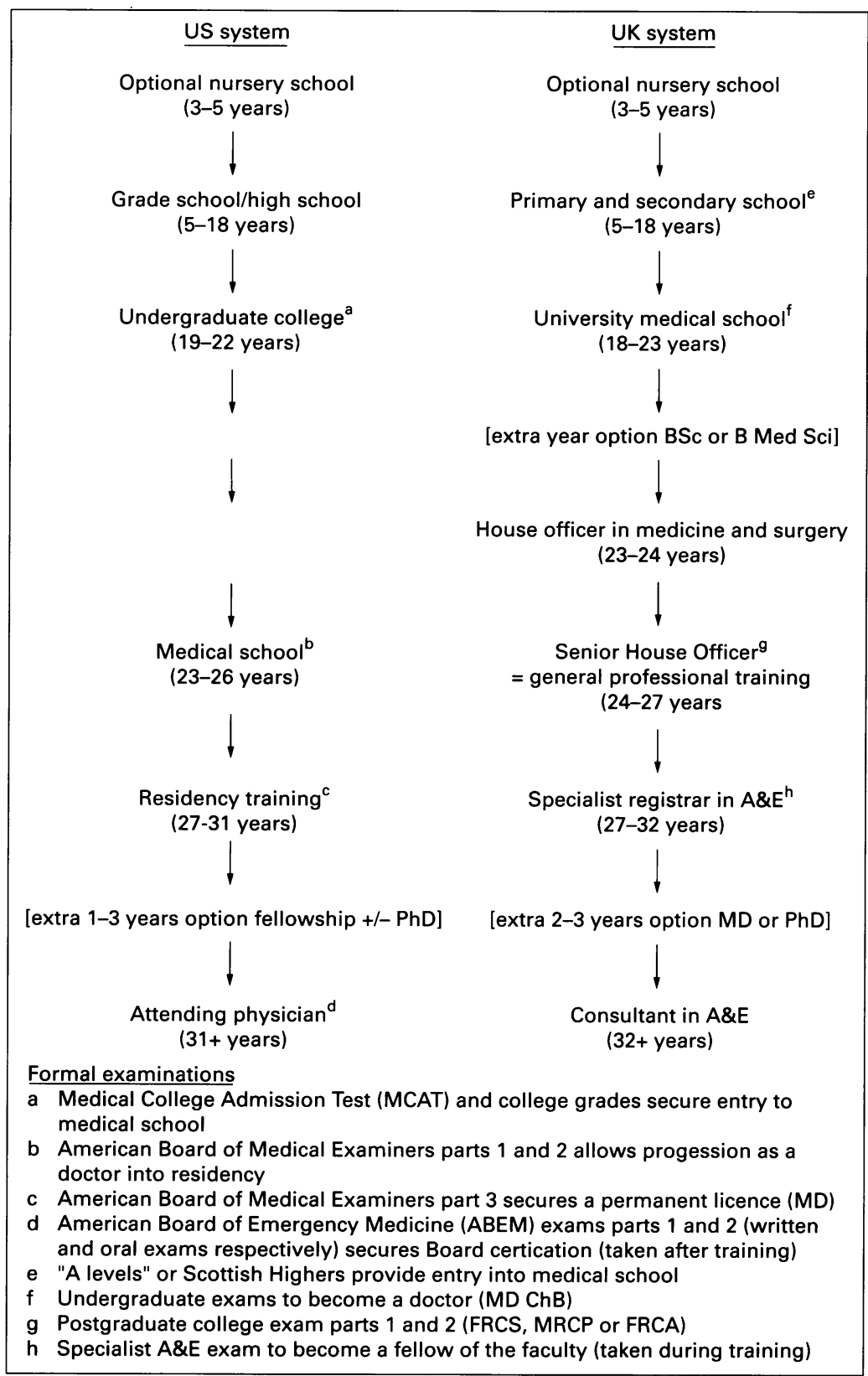

Figure 1 Typical career pathways in emergency medicine.

specialties. There are no formal examination requirements, other than those at medical school.

In the United Kingdom, entry to specialist training can only occur after house jobs and a period of general professional training in which a postgraduate qualification in either medicine (MRCP), surgery (AFRCS/MRCS), or anaesthetics (FRCA) has been obtained. In addition, it is virtually impossible to become a specialist $A \& E$ registrar without at least six months' experience in the specialty: the appointing committee needs to be convinced about the applicant's aptitude and commitment. Such thinking does not feature heavily within the American system, where a small attrition rate is accepted. ${ }^{26}$

\section{Supply and demand for specialist training}

Emergency medicine is expanding rapidly on both sides of the Atlantic, with the intention of enabling more comprehensive patient care to be directly or indirectly managed by fully trained specialists. ${ }^{78}$ Emergency medicine in the USA is, for a variety of reasons, a popular career choice. ${ }^{2}$ As a result, the supply of potential trainees has outstripped demand, causing fierce competition and ensuring that most training positions are easily filled. ${ }^{910}$ In the United Kingdom, competition for many career registrar posts is such that many trainees are now looking to try to obtain extra experience and research to secure entry. Paradoxically, considering the arguments driving recent changes in specialist registrar training, if this situation continues to develop, it will actually prolong training. ${ }^{34}$ The developing bottleneck at the point of entry into United Kingdom A\&E training needs to be addressed, although the problem has been eased to a certain extent by regulations allowing some time spent in a "locum against training" post to count towards training.

\section{Overall length of training}

The most obvious difference in training between the USA and United Kingdom relates to the length of postgraduate training. Seventy per cent of American residency programmes last three years and begin in the first postgraduate year, although $20 \%$ are aimed at residents who already have one previous year of postgraduate experience. ${ }^{1}$ Interestingly, a recent development has been the introduction of four year residency programmes. ${ }^{112}$ Initially treated with a certain degree of circumspection, these have gained acceptance, but currently only comprise $10 \%$ of programmes. ${ }^{213}$

United Kingdom specialist registrar training follows general professional training and lasts five years. The protracted training period in the United Kingdom has been partly addressed by changes implemented in the Calman report. ${ }^{34}$ The period of general professional training in the United Kingdom has no equivalent in the USA. Its opponents argue that it uses time which would be better spent in the $A \& E$ department and that it is an unnecessary extension of an already long training, teaching junior doctors skills which they may never use. Proponents argue that by encouraging junior doctors to experience several hospital jobs it allows them to make a more informed career choice at a more mature age. Interestingly, physicians in the USA enter specialist training at approximately the same age as those in the United Kingdom (fig 1). Furthermore, evidence suggests that the vast majority of American residency trained attending physicians remain in the specialty and are happy with their career choice. ${ }^{6}{ }^{14}$ The complaint that three years' training yields insufficient clinical experience is not widespread. Indeed, as in the United Kingdom, the most commonly cited complaints relate to a lack of training in administration and management. ${ }^{14-16}$

To a certain extent, transatlantic differences in the length of training reflect different philosophies. Emergency medicine trainees in the USA are being trained to help provide an "attending based" service, whereas in the 
Table 1 American and United Kingdom training requirements summarised

\begin{tabular}{|c|c|c|}
\hline & US residency & UK registrar training \\
\hline Entry requirement & Graduation from medical school & $\begin{array}{l}\text { At least } 3 \text { years postgraduate training, plus FRCS, MRCP or } \\
\text { FRCA }\end{array}$ \\
\hline Length of training & 3 or 4 Years & 5 Years \\
\hline Number of hospitals involved in training & Usually at least two hospitals & Always at least two hospitals, usually more \\
\hline Time in emergency department & At least $50 \%$ of residency (ie, $18-24$ months) & Not specified, but in practice, at least 3 years \\
\hline Paediatric requirement & Equivalent of 4 months paediatrics & 3 Months paediatrics \\
\hline Other out of service requirements & 2 Months of critical care rotations & $\begin{array}{l}3 \text { Months of each of the following, if not covered in initial } \\
\text { training: paediatrics, anaesthesia and intensive care, medicine and } \\
\text { coronary care, general/plastic/neurosurgery, trauma and } \\
\text { orthopaedics }\end{array}$ \\
\hline Hours of work & $\begin{array}{l}\text { Maximum } 60 \text { hours a week in the emergency } \\
\text { department }\end{array}$ & $\begin{array}{l}\text { Maximum } 56 \text { "full shift" hours a week in the emergency } \\
\text { department }\end{array}$ \\
\hline Supervision & Available immediately at any time & Variably available: usually not immediately available at night \\
\hline Teaching & At least 5 hours of formal teaching a week & No requirement \\
\hline Logbook & Personal record required, but no specified format & Logbook with standard format \\
\hline Assessment & At least every six months & Annual assessment \\
\hline Exams during training & ABME part 3, plus yearly "in-service" exams & Specialist exam in A\&E (FFAEM) \\
\hline Research & $\begin{array}{l}\text { Understanding of research methodology and } \\
\text { statistics }\end{array}$ & Involvement in several projects expected, but not specified \\
\hline
\end{tabular}

United Kingdom the only realistic current aim is for a "consultant led" service. Extra length of United Kingdom training may therefore be justified on the basis that all consultants are required to supervise and teach junior doctors in the same way as senior faculty members of a teaching programme in the USA. Indeed, in some respects, the United Kingdom senior registrar functions similarly to a newly appointed attending physician in America.

The cynic might argue that training structure is largely financially driven. In the United Kingdom, prolonged training allows more patients to be seen by junior doctors, whose rate of pay is significantly inferior to that of consultants. The American system demands that every patient presenting to the emergency department be seen at some stage by an attending physician. As a result, there are pressures for training to be as efficient and rapid as possible.

\section{Structure of training programmes}

The core content or curriculum for training in the USA is similar to that in the United Kingdom. ${ }^{17-19}$ Both systems recognise the need for out-of-service training in other departments (table 1). ${ }^{18-20}$ Formal American requirements relate to paediatrics and critical care (including coronary care and paediatric, surgical, and medical intensive care). Additionally, all programmes rotate through other key specialties and offer elective time in areas of personal interest. There is considerable variation between American training programmes in terms of the exact details of what is on offer. Interestingly, involvement in prehospital care and interhospital patient transfers receives more emphasis in the USA: most residencies require residents to spend time in ambulances and/or helicopters. Perhaps the addition of a mandatory prehospital care attachment, including a short period spent with the local ambulance service, would usefully broaden United Kingdom training.

Training in both systems is based within the emergency department. As the trainee progresses, a greater proportion of time is spent there. The vast majority of training programmes in the USA and United Kingdom rotate through more than one hospital. This is in acknowledgement of the benefits of allowing trainees to experience varied training environments.

Each residency programme has a minimum intake of six residents, such that even the smallest programme will be training at least 18 residents at any one time. ${ }^{20}$ In the United Kingdom, few programmes have more than six registrars based around even the larger teaching hospitals. ${ }^{21}$ This has considerable logistic implications for training.

\section{Comparison of day to day work}

The concept of shift work in emergency medicine transcends international boundaries. Regulations in the USA and United Kingdom limit the length of shifts and the number of hours worked per week. ${ }^{21-23}$ The basic work of American residents and United Kingdom registrars is to see and treat patients. American residents are closely supervised, such that every patient is additionally seen, or at least discussed with, an attending physician. Indeed, the Health Care Finance Association has recently mandated that all attending physicians must see and write or dictate a note on every patient seen by a resident in order to be reimbursed. The 24 hour presence of attending physicians within the emergency department provides residents with an enormous amount of informal clinical teaching. Although United Kingdom registrar training is also based around informal teaching, few $A \& E$ departments have sufficient consultants to allow their presence outside normal working hours. Opportunities for in-house teaching are therefore more limited, despite the longer training period. United Kingdom A\&E training would be enhanced by the introduction of formalised, regular, close supervision of registrars while they assess and treat patients, along similar lines to those adopted in the USA. This supervision would involve the consultant being present to observe the registrar while assessing and treating patients. Although the result would be an increase in the teaching workload of the supervising consultant, there would be an enormous benefit to the registrar. Also, it would add a regular check on the clinical skills of the registrar-such a check is arguably absent at the moment. 
Despite the fact that there is only a limited amount of data currently available, extrapolations suggest that junior doctors in the USA see approximately 4500 emergency patients during their training, whereas those in the United Kingdom see approximately 12000 patients. ${ }^{2024}$ Similar discrepancies appear to exist between the two systems as far as the number of practical procedures performed during training is concerned. ${ }^{24}{ }^{25}$ However, although both training programmes list procedures considered essential for training (see below), the number required of each has neither been defined nor agreed. The situation is further complicated in the United Kingdom by the fact that many procedures are performed unsupervised (for example, at times when no consultant is immediately available). Argument continues as to whether it is better training to see and treat a small number of patients supervised by a consultant, or a large number unsupervised. Close supervision may enable improvement of clinical skills, yet being left unsupervised may help to develop independent thinking. An obvious compromise within the United Kingdom training system would be to introduce an element of formalised regular consultant supervision, as suggested above.

The role of the United Kingdom registrar is somewhat different from that of the American resident. The former has far greater autonomy, in terms of being able to treat and discharge patients. In addition to receiving training, the United Kingdom registrar is simultaneously expected to spend much time acting as a trainer, supervising more junior doctors. ${ }^{24}$

\section{Salary and moonlighting}

American residency pay is remarkably similar to that of United Kingdom junior doctors, with a typical annual salary of around $£ 25000$. However, the American University system results in most doctors beginning residency with a loan of around $£ 70000$, as opposed to perhaps $£ 10000$ among United Kingdom graduates. As a result, having obtained a full licence, American residents are tempted to earn extra money by undertaking locum work. This work tends to be readily available and is extremely lucrative, a typical rate of pay being $£ 50$ per hour. The work is, however, usually completely unsupervised. More importantly, it is very tiring, adding to an already heavy workload. There has been much recent concern that such "moonlighting" significantly detracts from the educational aspect of residency and that it abuses financially vulnerable young doctors. ${ }^{26-30}$ United Kingdom junior doctors in $\mathrm{A} \& \mathrm{E}$ are, in comparison, fortunate enough to be relatively protected from the pressures of moonlighting. This is a result of constraints relating to the total number of hours worked and to a generally lesser degree of debt at the time of becoming a doctor.

Formal teaching and study leave

Formal classroom teaching for residents is a key feature of the American training programme. The residency review committee in emergency medicine requires each residency programme to provide at least five hours of classroom teaching a week. ${ }^{20}$ It further requires attendance to be documented and that rotas ("schedules") and other commitments be adjusted to allow all residents to attend at least $70 \%$ of the teaching. ${ }^{20}$ Residents are encouraged to provide part of this teaching for each other, under close guidance from attending physicians. The teaching may comprise lectures, seminars, audit meetings, journal reviews, and research presentations.

In the United Kingdom, there are guidelines and recommendations for the education of senior house officers, but there is no specific requirement for formal teaching of specialist registrars. ${ }^{31}{ }^{32}$ Such a requirement would be a valuable addition. Logistical difficulties may make implementation of regular classroom teaching difficult, but without it, the definition of the word "training" is perhaps stretched beyond that which is credible! The problem of only having a small number of trainers and registrars in one programme could be addressed by collaboration between hospitals within a region to enable a larger number of registrars to be gathered together for a formal teaching day once or twice a month. These meetings would be the responsibility of the chairman of the regional specialist training committee.

Despite a lack of formal teaching, United Kingdom training programmes allow registrars a half day per week for private study or research. Both the American and United Kingdom systems encourage attendance at regional and national meetings to present research. Similarly, completion of relevant courses (such as ATLS, ACLS, APLS, and PALS) is usually either expected or strongly encouraged.

\section{Administration and management}

Administration is a formal curriculum requirement in both the USA and the United Kingdom. However, evidence suggests that management training is a subject which is not particularly well covered. ${ }^{14-16}$ In the United Kingdom, the importance of management issues in training has been recognised such that a specific part of the specialist examination is devoted to testing knowledge and skills in this area. ${ }^{33}$ Similarly, the American Board of Emergency Medicine examinations include questions relating to administration and management.

\section{Research and training in academic emergency medicine}

It is expected that both the American resident and United Kingdom registrar will gain an understanding of research methodology and statistics during training. The principal objective of this is to produce emergency physicians capable of evaluating research published in peer reviewed journals. In the United Kingdom there is an implied expectation of trainee involvement in research. This is less true in the USA, owing to time constraints in a shorter training programme and acknowledgement of 
the reality that most emergency physicians will not pursue research after completing training.

While academic emergency medicine has taken great strides forward on both sides of the Atlantic, training for it is relatively poorly developed. Trainees wishing to pursue an academic career represent only a small minority in both systems. Although there are a few specific "lecturer" or "tutor" posts in the USA, most would-be academics are advised to target their applications to try to train in an institution with a recognised academic record. In the USA, publishing more than a handful of papers in peer reviewed journals during residency is likely to prove difficult, but following residency with a fellowship will provide better opportunities (see below). In the United Kingdom, the small proportion of trainees interested in research may find time to publish 50 or more articles. Research is encouraged by one year of full time research (for example, while obtaining an $\mathrm{MD}$ or $\mathrm{PhD}$ ), counting towards accreditation (see below).

\section{Examinations and assessment}

Medical examinations differ greatly between the USA and the United Kingdom. In the USA, successful passage through the first two parts of the examination of the American Board of Medical Examiners at medical school enables graduation and practice during residency as a physician with a "education limited" licence. The third (final) part of this examination is taken by all residents in all specialties during the first year of residency, after which application can be made for a permanent licence. The training emergency physician is unable to take specialist examinations until after residency. The two part American Board of Emergency Medicine examination is usually taken in the first year as an attending physician and has pass rates of $60 \%$ and $74 \%$ respectively. ${ }^{2}$ Success results in Board certification in emergency medicine (accreditation).

Additionally, all emergency medicine residents across the country are required to sit the same multiple choice question paper ("Inservice" examination) based upon the curriculum annually. While this is not a formal examination, residents and trainers receive individual scores and a national rank. This provides an incentive for regular study and allows residents and trainers to assess knowledge base, enabling improvement in identified areas of weakness. The spread of results for each programme also reflects the teaching provided.

In the United Kingdom, examinations in $\mathrm{A} \& \mathrm{E}$ continue to evolve. Having entered specialist training, there is no regular test of knowledge. It is generally agreed, however, that there is a need for some form of regular assessment. ${ }^{33-35}$ An equivalent in-service test after one or two years would certainly encourage directed reading, possibly lacking at present. It would provide trainers with an objective measure of progress at annual assessment and help to identify those training programmes in need of re-evaluation by the specialist advisory committee. Towards the end of the training period, the specialist examination in A\&E may be taken to gain fellowship of the Faculty of Accident and Emergency Medicine (FFAEM). ${ }^{33}$ This examination focuses more on understanding than on knowledge: testing understanding of management issues and research methodology in addition to assessing clinical competence (using objective structured clinical examination). Finally, on successful completion of five years of higher specialist training, a certificate of completion of specialist training in $\mathrm{A} \& \mathrm{E}$ is awarded.

Joint accreditation in emergency medicine and paediatrics was previously possible in the United Kingdom after extra training, but the situation now appears somewhat confused as a result of the introduction of recent changes. In the USA, it is possible to obtain joint Board certification by combining paediatric emergency medicine or internal medicine with emergency medicine in a special five year residency.

During each training programme, meetings between trainer and trainee to discuss progress are a regular feature. Both American and United Kingdom systems require trainees to keep a logbook of practical procedures they have performed. In the United Kingdom, a standardised logbook has been produced by the Faculty of A\&E Medicine and is used in the faculty examination. ${ }^{33}$ Although arguments about how many times any particular procedure should be performed in training are difficult to settle, a standardised logbook might be usefully introduced into residency programmes.

\section{Fellowships}

Exclusive to the American system, after residency attending physicians can apply to take up a "fellowship" for one to three years. These are mainly university posts, enabling further training within a subspecialty, including research (often aimed towards a $\mathrm{PhD}$ or a Masters degree in Public Health), prehospital care, administration, paediatrics, toxicology, critical care, and hyperbaric medicine. Such a post provides a foothold within the university system and is suited to those contemplating an academic career. The United Kingdom system has sufficient length and flexibility for equivalent subspecialty training and research to be incorporated within it.

\section{Recommendations for future United Kingdom training}

Many of the transatlantic differences in training for emergency medicine reflect different systems and more importantly, the different roles of the doctors that each aims to create. There are, nevertheless, positive attributes of each training programme which may be usefully applied to the other. As the specialty of emergency medicine develops, those responsible for training face an exciting challenge. If expansion continues apace in the United Kingdom as expected, it will be appropriate to consider implementing changes. These may include many of the features of the American training programmes currently rejected as 
being logistically impossible. To summarise, introduction of the following is recommended for United Kingdom training:

1 A mandatory prehospital care attachment.

2 Formalised regional weekly teaching programmes.

3 Formalised regular "one to one" consultant supervision of $\mathrm{A} \& \mathrm{E}$ trainees while they assess and treat patients.

4 "In-service" training examinations for all A\&E trainees.

We wish to thank the following for sharing their not inconsiderable experience: Dr M Allswede, Professor W Barsan, Dr C Chudnofsky, Dr J Cisek, Dr S Dronen, Dr K Little, Dr R Maio, and $M r M$ Rady.

JPW received a grant from the Ethicon Foundation Fund of the Royal College of Surgeons of Edinburgh to study training in Michigan. JEW received funding from the William Beaumont Hospital Foundation to study training in Scotland.

The views expressed in this article reflect the personal opinions of the authors and are not necessarily those of the Society for Academic Emergency Medicine, nor of the Faculty of Accident and Emergency Medicine.

1 Graduate medical education directory. Chicago: American Medical Association, 1996.

2 Rund DA. Synopsis for faculty. Michigan: American Board of Emergency Medicine, 1996.

3 Joint Committee on Higher Medical Training. Training in accident and emergency medicine. London: Joint Committee accident and emergency medicine. Lo

4 Department of Health. Hospital doctors: training for the future. The report of the working group on specialist medical training. London: Department of Health, 1993.

5 Williams MJ. Emergency department workload-a transatlantic comparison. F Emerg Med 1991;9:411-16

$6 \mathrm{Xu} \mathrm{G}$, Hojat M, Veloski J. Emergency medicine caree change: associations with performances in medical schoo and in the first postgraduate year and with indebtedness. Acad Emerg Med 1994;1:443-7.

7 Department of Health and Social Security, Joint Consultants Committee, Chairmen of Regional Health Authorities. Hospital medical staffing: achieving a balance. London: DHSS, 1986.

8 Department of Health and Social Security, Joint Consultants Committee, Chairmen of Regional Health Authorities. Hospital medical staffing: achieving a balance-plan for ties. Hospital medical staffing:
action. London: DHSS, 1987.

9 Martin ML. Applicant pool for emergency medicine Martin ML. Applicant pool for emergency medicine residency programs: information on minority
applicants. Ann Emerg Med 1996;27:331-8.

10 Granger NA, Renner BR. Applicant pool for emergency medicine residencies. Ann Emerg Med 1996;27:363-4.

11 Barsan WG, Levy RC. Duration of training in emergency medicine residency. Ann Emerg Med 1982;11:639-40.

12 Sloan EP, Strange GR, Jayne HA. United States emergency medicine residency length in 1986-87 and 1987-8. Ann Emerg Med 1987;16:862-6.

13 Levy RC. Four-year residency training redux. Am J Emerg Med 1988;6:415-16.

14 Wakeman MA, Hall KN, Levy RC. Descriptive analysis of residency-trained emergency medicine physicians. J Emerg Med 1991;9:379-84.

15 Driscoll P, Cope A, Miles SAD. Adequacy of senior registrar training in accident and emergency medicine over the last five years. Arch Emerg Med 1988;5:162-8.
16 Johnson G, Brown R, Howell M. Higher specialist training in accident and emergency medicine-past, present and future. J Accid Emerg Med 1997;14:104-6.

17 American College of Emergency Physicians, American Board of Emergency Medicine, Society for Academic Emergency Medicine. Core content for Emergency Medicine. Ann Emerg Med 1991;20:920-34.

18 Faculty of Accident and Emergency Medicine and Specialist Advisory Committee in Accident and Emergency Medicine. Curriculum for higher specialist training in Accident and Emergency Medicine. London: Faculty of Accident and Emergency Medicine. Londo

19 Board of the Faculty of Accident and Emergency Medicine. Guidelines for specialist training in accident and emergency medicine. London: Faculty of Accident and Emergency Medicine, 1996.

20 Residency Review Committee in Emergency Medicine. Program requirements for residency education in emergency medicine. American Council for Graduate Medical Education, 1996.

21 British Association for Accident and Emergency Medicine. The way ahead: accident and emergency services 2001. London: British Association for Accident and Emergency Medicine, 1992.

22 National Health Service Management Executive. Funior doctors: the new deal. London: NHS Management Executoctors: the 1991 .

23 Wols M, Kramer D. Resident service hours in emergency medicine. Acad Emerg Med 1995;2:124-7.

24 Wyatt JP. The role of the accident and emergency registrar. J R Soc Med 1994;87:697-700.

25 Dire DJ, Kietzman LI. A prospective survey of procedures performed by emergency medicine residents during a 36 month residency. J Emerg Med 1995;13:831-7.

26 Bencivenga $D$. To moonlight or not to moonlight? Intern Med Resident 1993;Jul/Aug:12-22.

27 Dronen SC. January/February 1994 President's Letter. Dallas: Council of Residency Directors Newsletter, 1994.

28 Langdorf MI, Bearie B, Ritter MS, Ferkich A, for the Council of Residency Directors Task Force on resident moonlighting. Emergency medicine resident moonlighting: a survey of program directors. Acad Emerg Med 1995;2: 302-7.

29 Langdorf MI, Bearie B, Ritter MS, Ferkich A for the Society of Academic Emergency Medicine In-service Examination Survey Task Force. National survey of emergency medicine resident moonlighting. Acad Emerg Med 1995;2:308-14.

30 Diebold SE, Ferraro CM. Moonlighting and student debt Acad Emerg Med 1995;2:330-1.

31 Academic Committee of the British Association for Accident and Emergency Medicine. Recommended teaching standards in accident and emergency departments. London: British Association for Accident and Emergency London: British
Medicine, 1991 .

32 Rodenberg $\mathrm{H}$. Education in accident and emergency medicine for senior house officers: review and recommendations. J Accid Emerg Med 1996;13:238-42.

33 Faculty of Accident and Emergency Medicine. Regulations relating to the specialty examination in accident and emergency medicine. London: Faculty of A\&E Medicine, 1994.

34 Department of Health. A guide to specialist registrar training. London: Department of Health, 1996.

35 Reynard K, McGowan A. Assessment of specialist registrars in A\&E-opportunities for change. J Accid Emerg Med 1997;14:107-9.

36 Faculty of Accident and Emergency Medicine. Training record for higher specialist trainees in accident and emergency medicine. London: Faculty of A\&E Medicine, 1995. 